\title{
Results of the Experimental Studies of Grain Cleaning with an Air-Spiral Separator
}

\author{
Sergey Shepelev ${ }^{1}$, Maksim Cheskidov ${ }^{1, *}$, Vladimir Chumakov $^{2}$, Aleksandr Gritsenko ${ }^{3}$, and Natalia \\ Shepeleva ${ }^{3}$ \\ ${ }^{1}$ South Ural State Agrarian University, Russia, 454080, Chelyabinsk region, Chelyabinsk, Lenin \\ Avenue, 75 \\ ${ }^{2}$ Kurgan State Agricultural Academy by T.S. Maltsev, Russia, 454080, 641300, Kurgan region, \\ Ketovsky district, Lesnikovo village \\ ${ }^{3}$ South Ural State University, 454080, Chelyabinsk region, Chelyabinsk, Lenin Avenue, 76.
}

\begin{abstract}
We have developed an air-spiral separator with a screw aspiration channel, which allows us to reduce the air consumption and specific quantity of metal per structure. We have established that the separation process is ensured at an air flow rate $V=7.1 \ldots 7.9 \mathrm{~m} / \mathrm{s}$ and the diameter of the working element $D=0.3 \mathrm{~m} /$ To ensure a pressure of $120.7 \ldots 133.4 \mathrm{~Pa}$ in the working element of the separator, the fan should ensure the initial air flow pressure $P=158.7 \ldots 175.4 \mathrm{~Pa}$. Our laboratory studies have established that the change in the product delivery volume uniformly affects the change in the output parameter at any speed value. We have found that the change in the product delivery volume has a larger effect on the change in the output parameter when the air flow rate increases. The relationship between the product delivery point and the air flow rate is almost linear and uniform.
\end{abstract}

\section{Introduction}

The performance of an agricultural enterprise largely depends on the safety of crops after harvesting [1-4]. The design capacity of post-harvest cleaning machines depends on the technological infrastructure of harvesting processes, the rate of grain maturing in the fields, and the moisture content of the grain delivered for cleaning [5-7]. Grain is cleaned and sorted both in air separators and air sieving machines. Cleaning with minimal grain damage and high productivity in air separators is most efficient [8,9]. Currently, air separators with a vertical or horizontal aspiration channel are used to clean grain based on the aerodynamic properties. In separators with a vertical aspiration channel, the concentration of components grows in the working area with an increase in delivery, which leads to a decrease in the technological efficiency of the air flow to $15-30 \%$. A distinctive feature of the separators with a horizontal aspiration channel is that their directions of gravity and aerodynamic force do not coincide, which reduces the likelihood of mutual collisions of grain heap particles. Commercial separators have a high performance and acceptable grain cleaning quality, but at the same time, they have a high specific quantity of

* Corresponding author: mister.aspirant@yandex.ru 
metal and significant air consumption, which leads to an increase in energy and operating costs.

The purchase of expensive separators by farms is not always expedient; to this end, the use of an air-spiral separator with a screw aspiration channel will allow us to reduce the air consumption and specific quantity of metal per structure [10]. The separation process in an air-spiral separator with a horizontal screw aspiration channel is as follows: the grain heap is delivered from the intake-loading device to the working element of the separator. Then, it is moved with the spiral conveyer towards the discharge window. The air flow supplied by the fan into the screw aspiration channel is directed towards the weed impurities discharge window. The air flow captures light particles and carries them into the window of the discharge connection, while the intake-loading device is constantly filled due to the continuous grain loading, which prevents the air flow from escaping through the intakeloading device. Grain without light weed impurities is moved by the spiral conveyer into the window to discharge the cleaned grain. The cleaning quality is increased because the approach air flow moves along a screw trajectory and, besides, the grain layer is constantly mixed by the spiral conveyer in the working element. When the particles move along the screw aspiration channel under the action of the air flow, they are influenced by the inertial force, as a result of which they are carried to the walls of the working element of the separator. However, the processes running in the developed separator during the grain heap cleaning are currently under-investigated.

\section{Materials and Methods}

To study and set the main parameters: the process of pre-cleaning of the grain heap from weed impurities; the air-spiral separator with a horizontal screw aspiration channel, and its operating mode, we developed a laboratory setup to simulate the real processes of grain cleaning from weed impurities. To simulate the processes of grain cleaning in air separators, it is most effective to use the modern ANSYS CFX software product [11-15]. Based on the analytical description of the process of grain cleaning from weed impurities in the air-spiral separator, we determined that the separation process is ensured at an air flow rate $V=7.1 \ldots 7.9 \mathrm{~m} / \mathrm{s}$ and the diameter of the working element $D=0.3 \mathrm{~m} /$ To ensure a pressure of $120.7 \ldots 133.4 \mathrm{~Pa}$ in the working element of the separator, the fan should provide the initial air flow pressure $P=158.7 \ldots 175.4 \mathrm{~Pa}$.

We established that the diameter of the working element of the air-spiral separator depends on the air flow rate; the paths of the particles in the screw aspiration channel depend on the hovering velocity of the particles; the air flow pressure in the screw aspiration channel decreases with an increase in the distance to the outlet of the cleaned grain. Using the air-spiral separator, one can quickly and efficiently clean the grain heap from weed impurities. At the same time, the moisture content in the cleaned grain decreases, which contributes to its better preservation.

The laboratory and production tests of the air-spiral separator with a horizontal screw aspiration channel proved that the cleaning quality is directly influenced by such process parameters as the spiral conveyer speed (rpm); the volume of the delivered products, $(\mathrm{kg} / \mathrm{h})$; the air flow rate, $(\mathrm{m} / \mathrm{s})$; and the product delivery point. To evaluate the paths of the particles obtained theoretically and to determine the regularities of changes in the cleaning quality depending on the main parameters, we carried out a comprehensive factor $2^{\mathrm{k}}$-type experiment. The main level and intervals of variation were selected based on the preliminary experiments and are presented in Table 1 . The criterion $\mathrm{Y}$ - the mass of the weed impurities separated from the grain heap - was adopted as the experimental response.

Table 1. Coding of the experimental factors 


\begin{tabular}{|c|c|c|c|c|}
\hline \multirow[b]{2}{*}{ Characteristics } & \multicolumn{4}{|c|}{ Factors $X_{j}$} \\
\hline & $\begin{array}{l}\text { Spiral conveyer } \\
\text { speed, } X_{1}(\mathrm{rpm})\end{array}$ & $\begin{array}{ll}\text { Product } & \\
\text { delivery } & \\
\text { volume, } & \mathbf{X}_{2} \\
(\mathrm{~kg} / \mathrm{h}) & \\
\end{array}$ & $\begin{array}{l}\text { Air flow rate, } \\
X_{3}(m / s)\end{array}$ & $\begin{array}{l}\text { Raw } \\
\text { materials } \\
\text { delivery } \\
\text { point, } \mathbf{X}_{4}\end{array}$ \\
\hline $\begin{array}{l}\text { Basic level (center of } \\
\text { the experiment) }\end{array}$ & 60 & 400 & 5.89 & $c_{1}$ \\
\hline Variation interval $\Delta_{\mathrm{i}}$ & 40 & 200 & 1.61 & 1 \\
\hline Lower level & 20 & 200 & 4.28 & 1 \\
\hline Upper level & 100 & 600 & 7.5 & 3 \\
\hline $\begin{array}{l}\text { Designations of the } \\
\text { coded factors }\end{array}$ & $\mathrm{X}_{1}$ & $\mathrm{X}_{2}$ & $\mathrm{X}_{3}$ & $\mathrm{X}_{4}$ \\
\hline
\end{tabular}

The transition from the actual values of the factors to the coded dimensionless values is carried out according to the well-known formula:

$$
x_{i}=\left(X_{i}-X_{i}^{0}\right) / \Delta X_{i}
$$

where $\mathrm{x}_{\mathrm{i}}$ is the coded value of the factor; $X_{\mathrm{i}}$ is the actual value of the factor; $X_{i}^{0}$ is the value of the basic level; $\Delta X_{i}$ is the variation interval.

One of the prerequisites for carrying out the comprehensive factor experiment is the ability to control independent variable parameters $\left(\mathrm{X}_{1}, \mathrm{X}_{2}, \mathrm{X}_{3}, \mathrm{X}_{4}\right)$. To control the spiral conveyer speed, we used the NMRV motor-reducer and the HYUNDAI N700E frequency converter, which allowed us to change the spiral conveyer speed within a wide range. To monitor the speed, we used a digital photo-tachometer, and the air flow rate - the MMN micromanometer with a Pitot tube and throttle valves on the fan. The experiment was carried out with three repetitions, where the mass of the separated weed impurities and the grain cleaning degree were determined using a balance and a set of sieves. A sample of Tertsia wheat was selected for the experiment.

\section{Results}

According to the experimental research program, we determined the physical and mechanical properties of grain; the results are presented in Table 2.

Table 2. Physical and mechanical properties of grain

\begin{tabular}{|l|c|}
\hline \multicolumn{1}{|c|}{ Indicator } & Indicator value \\
\cline { 2 - 2 } & Wheat \\
\hline Average linear dimensions of seeds, $\mathrm{mm}$ & 2.9 \\
thickness & 3.2 \\
width & 6.1 \\
length & 3.84 \\
\hline Equivalent diameter, $\mathrm{mm}$ & 63.7 \\
\hline Mass of 1,000 grains, $\mathrm{g}$ & 18.0 \\
\hline Grain moisture content, \% & 7.8 \\
\hline Weed impurities content, \% & \\
\hline
\end{tabular}

The experiments have shown that when the grain is cleaned, in most cases, there is a complete separation of light weed impurities (parts of stems, chaff, dust, etc.), partial separation of cracked and shrinked grain (up to $50 \%$ ), weed seeds.

Based on the experiment results, we built a coded regression equation for $\mathrm{Y}$ - the separated weed impurities:

$$
\mathrm{Y}=65.94+10.09 x_{1}-20.55 x_{2}+54.57 x_{3}-2.86 x_{4}+5.16 x_{1} x_{3}-20.43 x_{2} x_{3}
$$


The influence of the factors on the mass of the separated weed impurities is shown in Figure 1, where b1 is the spiral conveyer speed, b2 is the product delivery volume, b3 is the air flow rate, b4 is the product delivery point, b13 and b23 are the relationship of the factors.

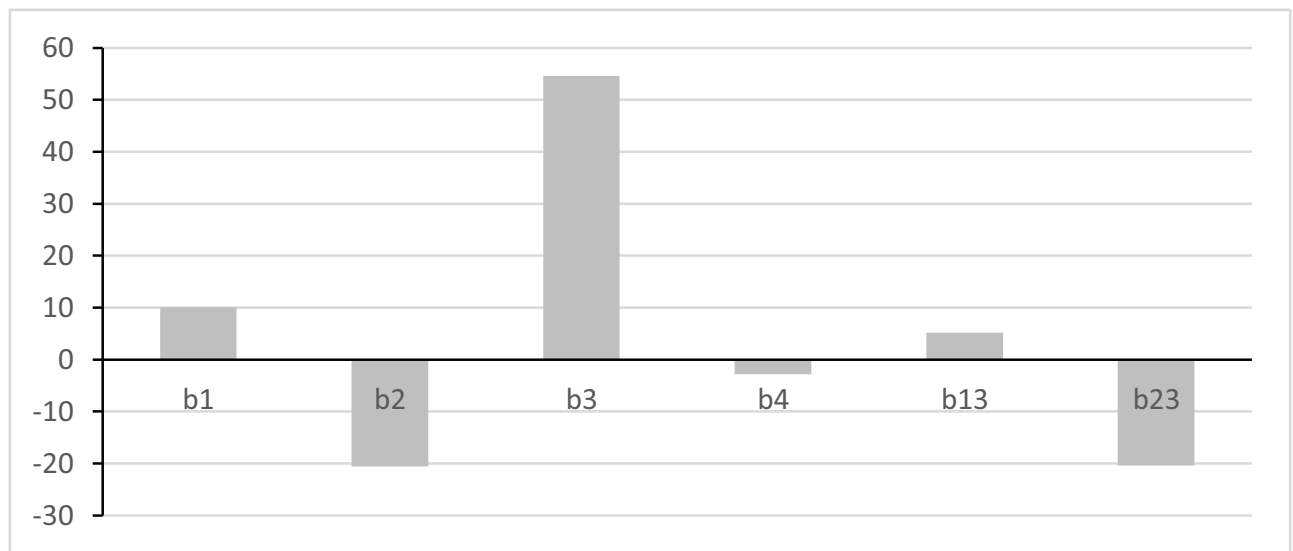

Fig. 1. The influence of the factors on the mass of the separated weed impurities

The mass of the separated weed impurities is mostly influenced by the air flow rate. For further use of the obtained equation, it should be presented in a decoded form. To this end, the coded values are replaced with the decoded ones. The decoded equation is as follows:

$$
\mathrm{Y}=-223.18-0.22 n-0.27 Q+54.47 V-2.86 h_{1}+0.08 n V-0.06 Q V
$$

We built response surfaces to analyze the resulting model using the Maple 2016 software. We can see on the response surface of the relationship between the speed and the product delivery volume (Figure 2) that the change in the product delivery volume uniformly affects the change in the output parameter at any speed value. 

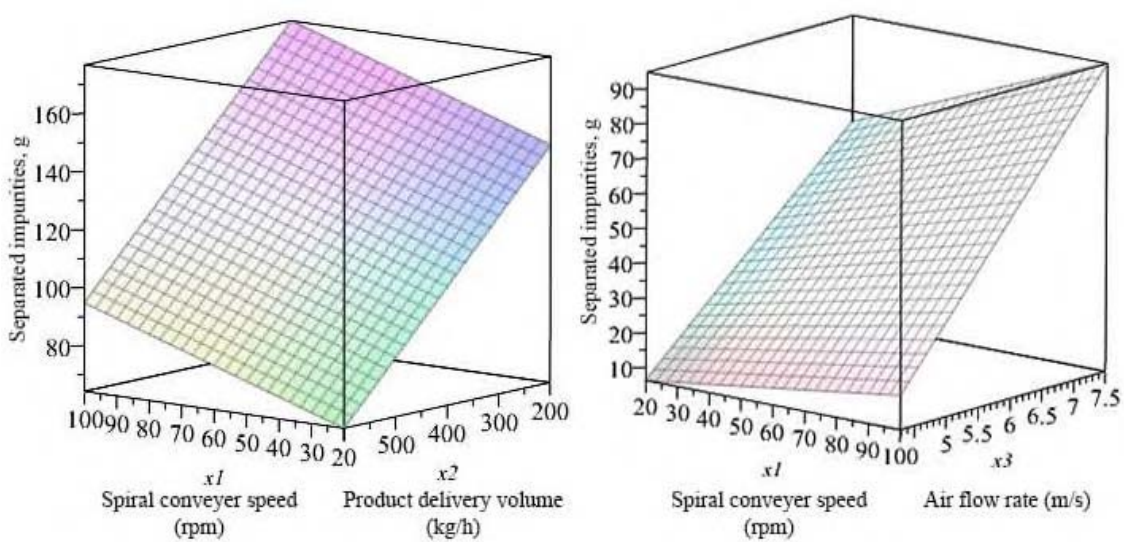

Spiral conveyer speed Air flow rate $(\mathrm{m} / \mathrm{s})$

$(\mathrm{pm})$
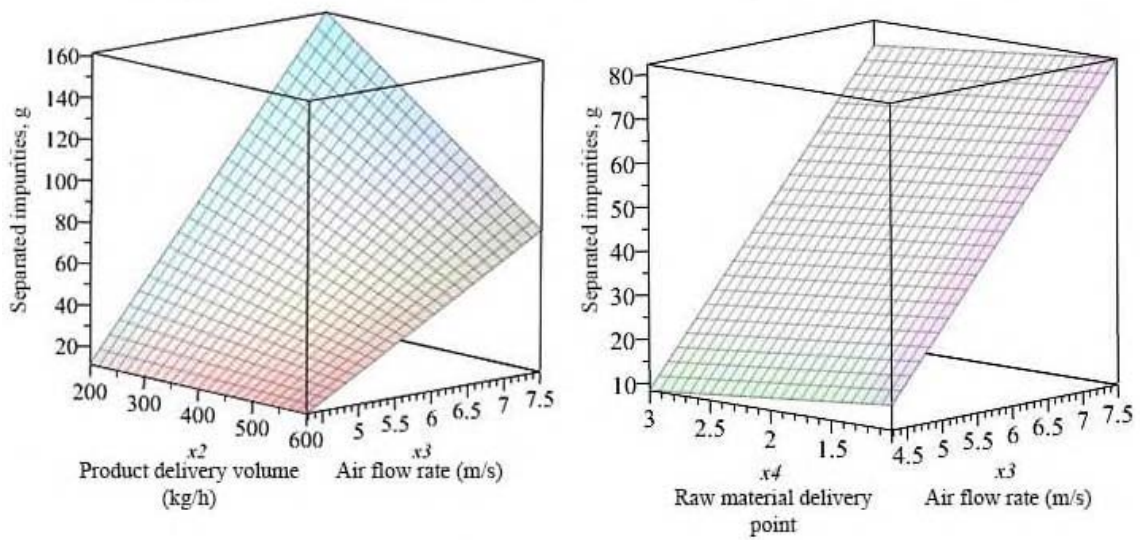

Fig. 2. The dependence of the cleaning quality on the design parameters and the operating mode of the air-spiral separator

\section{Conclusions}

The study of the relationship between the speed and the air flow rate showed that a change in the air flow rate uniformly affects the change in the output parameter at any speed value. We established that the change in the product delivery volume has a greater effect on the change in the output parameter with an increase in the air flow rate. The relationship between the product delivery point and the air flow rate is almost linear and uniform.

During the operation of the air-spiral separator prototype with a capacity of $680 \mathrm{~kg} / \mathrm{h}$, light weed impurities are completely separated from the grain heap with the moisture content of $18 \%$ and the contamination of $7.8 \%$, while the content of whole grain in the waste does not exceed $1.5 \%$. Thus, the regression model resulting from the implementation of the multifactor experiment adequately describes the process of grain cleaning from weed impurities in the air-spiral separator with a horizontal screw aspiration channel. The maximum influence on the grain cleaning quality is exerted by the air flow rate, the mass of the grain heap delivery per unit of time, and the speed of the spiral conveyer. With an increase in the mass of the grain heap delivery per unit of time, the cleaning quality decreases. The performance of the separator can be improved by increasing the number of working elements. 
We determined that the use of the developed installation in production conditions allowed us to clean the grain heap with $7.8 \%$ contamination. The annual savings due to the reduction of direct operating costs amounted to 180 thousand rubles or 220 rubles per one ton of cleaned grain.

\section{References}

1. V. Shepelev, S. Shepelev, Z. Almetova, Method of justification of the grain cleaning assembly performance. Research in Agricultural Engineering (2018)

2. A. Kliuchnikov, Development of new method of drying at energy-saving universal dryer to improve quality of crops used in fodder production/ Engineering for Rural Development, 18, 105-111 (2019) doi: 10.22616 / ERDev2019. 18.N125

3. M. Naumenko, S. Sokol, D. Filipenko, Numeric model of the grain mixture flow in a cylindrical sieve which revolves around the inclined axis. INMATEH - Agricultural Engineering, 56(3), 67-74 (2018)

4. M. Chrigui, A. Hidouri, A. Sadiki, J. Janicka, Unsteady Euler/Lagrange simulation of a confined bluff-body gas-solid turbulent flow. Fluid Dynamics Research, 45(5), 1-27 (2013) doi: 10.1088/0169-5983/45/5/055501

5. S. D. Shepelev, V. D. Shepelev, Z. V. Almetova, N. P. Shepeleva, M. V. Cheskidov, Modeling the Technological Process for Harvesting of Agricultural Produce. IOP Conference Series: Earth and Environmental Science, 115(1), 012053 (2018) doi: 10.1088/1755-1315/115/1/012053

6. C. Bracacescu, P. Gageanu, G. Bunduch, A. Zaica, Considerations on technical equipment used for cleaning and sorting seed mixtures based on aerodynamic principle. Engineering for Rural Development, 17, 39-44 (2018) doi: 10.22616 / ERDev2018. 17.N044.

7. S. Shepelev, V. Shepelev, Z. Almetova, Optimization of Technical Equipment for Crop Sowing Processes. Procedia Engineering (2016)

8. A. Butovchenko, A. Doroshenko, A. Kol'Cov, V. Serdyuk, Comparative analysis of the functioning of sieve modules for grain cleaning machines E3S Web of Conferences, 135, 01081 (2019) doi: 10.1051 / e3sconf/ 201913501081

9. A. A. Folami, E. N. Obioha, A. Adewole, Performance evaluation of a developed riceprocessing machine. Journal of Agricultural Engineering, 47(3), 506, 171-176 (2016) doi: $10.4081 /$ jae.2016.506

10. S. D. Shepelev, M. V. Cheskidov, I. Yu Novikova, F. N. Grakov, N. A. Kuznetsov, IOP Conference Series: Materials Science and Engineering (2019) DOI: $10.1088 / 1755-1315 / 115 / 1 / 012053$

11. A. Grishkov, E. Chebotarev, A. Boiko, Selection and justification of the design of polymer sieves of air-sieve machines. E3S Web of Conferences, 126, 00034 (2019) doi: 10.1051/e3sconf/201912600034.

12. L. A. Rakhmanin, A. V. Zuev, A. Y. Petrov, A. A. Aksenov, M. H. Nguyen, The investigation of absolute flow non-uniform velocity distributions influence at the centrifugal compressor axial radial impeller inlet using numerical calculation methods in ANSYS CFX. E3S Web of Conferences, 140, 05008 (2020) DOI: 10.1051 / e3sconf / 201914005008.

13. M. Alletto, M. Breuer, One-way, two-way and four-way coupled LES predictions of a particle-laden turbulent flow at high mass loading downstream of a confined bluff 
body. International Journal of Multiphase Flow, 45, 70-90 (2012) doi: 10.1016/j.ijmultiphaseflow.2012.05.005

14. F. Greifzu, C. Kratzsch, T. Forgber, F. Lindner, R. Schwarze, Assessment of particletracking models for dispersed particle-laden flows implemented in OpenFOAM and ANSYS FLUENT, Engineering Applications of Computational Fluid Mechanics, 10(1), 30-43 (2016) doi: 10.1080/19942060.2015.1104266

15. W.-F. Yang, C. Qiang, F. Wang, L. Li, W. Deng, X. Zhang, Three-dimensional CFD simulations to study the effect of impeller geometry on internal flow field in ADS upward spiral flow target, Journal of Nuclear Science and Technology, 55(12), 13811392 (2018) doi: 10.1080/00223131.2018.1512424. 